\title{
FINITUDES E INFINITUDES EM FOUCAULT: apontamento metodológico para o impasse empírico- transcendental
}

\author{
Ms. Roberison Wittgenstein Dias da Silveira \\ Doutorando do curso de Pós-Graduação Geografia \\ Instituto de Geociências, Unicamp, CP 6152, CEP 13087-970 - Campinas (SP)- Brasil \\ silveira_r@yahoo.com.br
}

Prof. Dr. Antonio Carlos Vitte, vitte@uol.com.br

\begin{abstract}
RESUMO
Este artigo indica uma via importante de análise para além das estruturas determinantes da ciência na consideração primeira de uma materialidade posta e inelutável, uma das premissas que o próprio Foucault aponta como pertencente ao quadro geral de princípios norteadores da epistémê moderna. Aqui, na mudança geral da epistémê defendida por Foucault (2002), não se determinam exclusivamente as alterações gerais da realidade pelo conjunto material disposto. Como média de uma equação, a ordem estabelecida por trás de todo fenômeno identificado é a expressão de um confluir entre uma materialidade sensivelmente identificada e os atributos de uma reflexão sobre esta mesma materialidade. Nesse meio-termo, no confluir destas variáveis justapostas, se desenvolvem as variações da cultura, o espaço mesmo de construção e redefinição incessante das condições de existir e de conhecer. Mais do que primaria observação da materialidade, a arqueologia usada no reconhecimento da epistémê geral é a mediana de uma realidade que se mostra maior do que as tentativas de por um ou outro caminho entendê-la.
\end{abstract}

Palavras-chave: Finitude e Infinitude; epistémê; modernidade; empírico-transcendental; arqueologia das ciências

\begin{abstract}
Este artículo intenta mostrar un importante modo de análisis más allá de las estructuras determinantes de la ciencia en la consideración de una propuesta estrictamente materialista, una de las premisas señaladas por Foucault como perteneciente al marco general de principios rectores de la epistémê moderna. Aquí, en el cambio general de la epistémê defendida por Foucault (2002), no se determinan exclusivamente los cambios generales de la realidad por las disposiciones materiales. Como media de una ecuación, el orden establecido detrás de todo el fenómeno identificado es la expresión de una confluencia de una materialidad sensiblemente identificada y los atributos de una reflexión sobre esta misma materialidad. En esto medio-termo, en la confluencia de estas variables yuxtapuestas se desarrolla las variaciones de la cultura, el terreno de la construcción y la constante redefinición de las condiciones de existencia e conocimiento. Más que la observación primaria de la materialidad la arqueología utilizada en el reconocimiento de la epistémê general es la mediana de una realidad que se muestra más complexa que los intentos de por una o otra manera entenderlo.
\end{abstract}

Key words: Finitud y Infinitud; epistémê; modernidad; empírico-trascendental, arqueología de las ciencias

\section{RESUMEN}

This articleit aims to show how the discussion of this work communicates an important way of analysis beyond the determinate structures of science in the first consideration of a constitutive materiality, one of the many premises that Foucault points as belonging to the general framework of guiding principles of modern epistémê. Here, in general change of epistémê defended by Foucault (2002), does not determine only the general changes of reality by all material provisions. As an average equation, the established order behind the whole phenomenon is the expression of a meet between a constitutive materiality and the attributes of the reflection on this materiality. In this half-term, in the confluence of these juxtaposed variables, develop the variations of culture, the construction and incessant redefinition of the conditions to exist and to know. More than primary observation of materiality and rather than pure presentation of the readings made on these codes, the archaeology used in recognition of Foucault's general epistémê is the median of a reality that is more complex than the attempts by understand it for one or another way alone.

Palabras-clave: Finite and Infinite; epistémê; modernity; empirical-transcendental; archaeology of sciences

\section{Introdução}

Na discussão entre finitudes e infinitudes em “As Palavras e as Coisas” de Foucault, o problema colocado à epsitémê moderna de pensar uma ontologia da realidade e do saber. Em verdade, a obra de Foucault (2002) oferece uma resposta metodológica para o desafio de compreender a modernidade e o avanço do saber sem as limitações impostas pelo curso de um pensamento que então se pretende analisado. 
Importante, esta apresentação metodológica vai de encontro ao problema colocado pelo curso da história da filosofia, o problema entre o empírico e o transcendental.

Pensando objetivamente sobre a modernidade e a possibilidade de uma análise histórica sobre a realidade e o saber nesta epistémê, encontramos um campo largo de reduções que apontam para um continuum posto pelo desenvolvimento das formas de produção e o rebatimento destas na maneira de pensar e agir para e com a realidade. Contudo, numa perspectiva filosófica, a visão de uma história materialmente dada é o limite da própria história e de sua dinâmica. A primazia de uma materialidade tomada como constitutiva e primeira é um arbítrio filosófico, a resposta dada pela própria modernidade ao problema empírico-transcendental; a redução limitadora que coloca o transcendental no verso de uma página empírica.

A modernidade não acaba por que as diretrizes materiais não mudam ou não acaba por que continuamos acreditando que a transformação reside nessa mudança? O homem é o que elaboramos em nossas construções intelectuais guiadas pelo pensamento moderno ou esta forma de enxergar o homem não é nada além do que a visão de um tempo passageiro, que com ele nos levará? Curioso é ver que imaginamos rompida a imutabilidade, mas defendemos tão ardentemente nossas convicções sobre o homem e a realidade que não daríamos, de bom grado, cabo do que agora nos parece uma explicação sóbria e legítima sobre ambos. Responder e refletir sobre estas questões é a busca que nos colocamos com a apresentação de uma outra perspectiva em Foucault (2002).

O desafio de Foucault em sua "As palavras e as coisas" é mostrar de que maneira se operaram as mudanças gerais da realidade que conduziram o pensamento à modernidade. Não obstante, a maneira, ou melhor, o método empregado na reconstrução histórica deste processo lança no campo da análise científica uma forma de proceder com o objeto histórico sem reduzi-lo ao papel determinante da materialidade ou, em outras palavras, ao reduto produtivo-econômico e seu rebatimento material. Por isso, destacamos neste artigo não só a identificação e o curso da epistémê moderna, mas também a forma com que o autor se abre para uma perspectiva analítica que pretende ver para além de um disposto quadro de finitudes e materialidades, tentando, de algum modo, redefinir o papel do transcendente na explicação e mesmo na existência da realidade. Sobre as possibilidades abertas por esta visão e a discussão que ela nos leva trataremos depois, no momento, voltamos as nossas atenções para o processo descrito por Foucault (2002).

\section{A epistémê geral do século XVI: a estrutura a ser rompida}

Ao contrário da aparente continuidade defendida pela visão histórica, o autor nos fala de duas grandes descontinuidades entre o período clássico e o advento da modernidade. Embora a superfície revele uma semelhança, a "arqueologia", a base geral dada por aquele confluir explicitado, se mostra bem diferente, com profundas e importantes rupturas.

... toda esta quase-continuidade ao nível das idéias e dos temas não passa, certamente, de um efeito de superfície; no nível arqueológico, vê-se que o sistema das positividades mudou de maneira maciça na curva dos séculos XVIII e XIX. Não que a razão tenha feito progressos, mas o modo de ser das coisas e da ordem que, distribuindo-as, oferece-as ao saber, é que foi profundamente alterado. (FOUCAULT, 2002, p. XIX)

Na análise da constituição da modernidade aponta primeiro as características vigentes até o século XVI, quando da ruptura para uma epistémê clássica. A disposição geral dessa epistémê rompida é a similitude, a aproximação entre o divino e o terreno, um quadro de semelhanças que ligava todos os elementos da realidade. Estas similitudes podem ser divididas em quatro principais figuras de articulação: a convenientia, que funcionaria como uma espécie de contato, pelo qual se ligam e se comunicam as coisas em sua proximidade, em última análise, tem uma ligação com a disposição, o arranjo espacial, dizendo respeito, portanto, ao exterior mais do que ao interior das coisas; a aemulatio, que se avizinha à convenientia, uma vez que também se liga à espacialidade, só que, nesse caso, se manifesta mais como 
uma reprodução, um espelho que, ainda que represente graus diferenciados, conduz à semelhança os elementos refletidos; a analogia, que, poderosa por estender seu domínio para além das similitudes do visível, pode e corresponde ao interior, aos processos e as leis internas dos elementos, constituindo a base de uma incisiva análise interpretativa e colocando o homem numa posição privilegiada em vista de sua possibilidade de comunicação com todo o existente; por fim, a simpatia, que conduz os elementos ao mesmo, à homogeneidade descrita pela anulação das individualidades, sendo, todavia, contrabalançado pela antipatia, evitando, em última instância, a igualdade e unidade irremediável entre todo o existente.

Estas figuras, alusivas ao processo de similitudes imperante em todo o período, não poderiam subsistir sem uma assinalação. Os signos, marca de todo existente, garantem coerência a toda semelhança, uma vez que assinalam o visível indicando possíveis sentidos e revelando processos e leis do invisível. Segundo Foucault (2002), é esta a forma geral da epistémê que se dispõe ao século XVI; é por ela que se limitará a investigação ao mesmo, à referências sempre restritivas, já que por similitudes se apreende o novo, aquilo que figura no universo dos signos e suas possibilidades explicativas. A magia, buscando a explicação inatingível num universo limitado de semelhanças, tomará conta do saber; a retórica, expressão dos signos lingüísticos, será a expressão de um conhecimento mantido pela ordem da palavra, pelo que impõe como verdade o conjunto de palavras garimpadas da Antigüidade.

A linguagem faz parte da grande distribuição das similitudes e das assinalações. Por conseguinte, deve, ela própria, ser estudada como uma coisa da natureza. Seus elementos têm, como os animais, as plantas ou as estrelas, suas leis de afinidade e de conveniência, suas analogias obrigatórias. (FOUCAULT, 2002, p. 48)

O papel fundamental da linguagem é evocado na função explicativa. Como parelha as coisas existentes, a linguagem será referência de toda análise. A partir dela se disporá ao homem a possibilidade aberta de comentar e analisar o mundo. É este saber especulativo, mantido no universo da retórica e ligado a magia, que desmoronará com o período Clássico; é esta epistémê que se vê rompida nos escritos de F. Bacon e Descartes.

\section{A epistémê clássica: em busca da ordem}

Rompendo uma relação que estabelece a linguagem como similar as coisas, instaura-se o período Clássico. A linguagem avança como representação, colocando sobre a mesa uma nova disposição dividida em significação e significado. Não bastará ao conhecimento revirar páginas envelhecidas de valiosos pergaminhos; o tesouro, reside então no mundo; a linguagem, subsiste como representação dos significantes reconhecidos. Apesar de apontar Dom Quixote e sua jornada ficcional como o primeiro traço de uma cisão da linguagem com as coisas, Foucault (2002) apontará Bacon (1561-1626) e Descartes (15961650) como centrais na consolidação da nova epistémê:

Encontra-se já em Bacon, uma crítica da semelhança. Crítica empírica, que não concerne às relações de ordem e de igualdade entre as coisas, mas aos tipos de espírito e às formas de ilusão às quais podem estar sujeitas. (...) São os "ídolos". Os "ídolos da caverna e do teatro" fazem-nos crer que as coisas se assemelham ao que aprendemos e às teorias que formamos para nós; outros ídolos fazem-nos crer que as coisas se assemelham entre si.

A crítica cartesiana da semelhança é de outro tipo. Não é mais o pensamento do século XVI inquietandose diante de si mesmo e começando a se desprender de suas mais familiares figuras; é o pensamento clássico excluindo a semelhança como experiência fundamental e forma primeira do saber, denunciando nela um misto confuso que cumpre sempre analisar em termos de identidade e de diferença, de medida e de ordem. Se Descartes recusa a semelhança, não é excluindo do pensamento racional o ato de comparação, nem buscando limitá-lo, mas, ao contrário, universalizando-o e dando-lhe assim sua mais pura forma. (FOUCAULT, 2002, p. 71-72) 
Identidade e diferença guiam essa comparação. Em Descartes (1983), a apresentação das diferenças, os aspectos negativos e, enfim, o valor das identidades, aquilo que reagrupa o conhecimento em seu caráter positivo, constituem a chave de toda a ordenação clássica, esse desafio que se colocará aos homens dos séculos XVII e XVIII. A ordenação do mundo é disposta ao pensamento numa fórmula cartesiana que sai do simples para atingir o complexo. Não basta mais o limitado apontamento da semelhança por figuras analógicas ou convenientes, é preciso a acuidade matemática, a ordem apreendida num jogo de identidades e diferenças.

Há, nesse processo, uma divisão entre história e ciência. Não interessa à ciência a simples apresentação seqüencial dos fatos, era preciso uma ordenação, uma análise que permitisse por acúmulo de diferenças e identidades uma investigação metodicamente coordenada. Fazer ciência é, em última análise, a capacidade de reconhecer as variações e o constante no estabelecimento de uma série ou agrupamento. O pensamento é aqui central, é ele, pela claridade do método, que é responsável pelo reconhecimento e fundação de signos válidos. A verdade, antes buscada na semelhança, se revela na ordem, na possibilidade aberta pelo pensamento de comandar e apreender o exterior e o íntimo da realidade. É nessa base que se constituirá a máthêsis, "ciência universal da ordem e da medida", o sentido último de todo o emprego analítico do pensamento. O signo lingüístico, como representação, servirá a este propósito, deixará de ser uma "figura do mundo" para nele apontar as diferenças e identidades tão caras à ordenação.

Na idade clássica, servir-se de signos não é, como nos séculos precedentes, tentar reencontrar por sob eles o texto primitivo de um discurso afirmado, e reafirmado, para sempre; é tentar descobrir a linguagem arbitrária que autorizará o desdobramento da natureza no seu espaço, os termos últimos de sua análise e as leis de sua composição. O saber não tem mais que desencravar a velha Palavra dos lugares desconhecidos onde ela se pode esconder; cumpre-lhe fabricar uma língua e que ela seja bem-feita isto é, que, analisante e combinante, ela seja realmente a língua dos cálculos. (FOUCAULT, 2002, p. 86)

A linguagem, formada a partir do duplo significante e significado, é representação, pode, portanto, abster-se do mundo ao mesmo tempo em que figura como passível de ordenação. Ora, os signos, agora representações, podem e incitam representações sobre eles mesmos. Isto é possível porque o signo existe, ainda que numa esfera distinta ao mundo, melhor ainda, de uma maneira singular e com regulações próprias; ao mesmo tempo em que apontam ou representam algo, aparecem, existem e são passíveis também de novas representações e, mais ainda, de ordenação. É isso que Foucault (2002) chamará de "representação reduplicada", essa abertura do pensamento sobre si mesmo e sem os limites tautológicos da epistémê anterior. É nesta representação que a similitude desempenhará seu novo papel, a de manter ligados e possíveis as conexões entre o significante e o significado, de permitir o conhecimento sem com ele se confundir. Se colocará, assim, a semelhança como vizinha à imaginação, na medida em que esta última funciona para a representação como este acessório indispensável e ao mesmo tempo distante do conhecimento. Foucault nos dirá que a função da semelhança e da imaginação na mathêsis se estabelece nos segmentos analíticos que se propagaram na direção da natureza e da natureza humana.

Se as noções de natureza e de natureza humana tiveram na idade clássica uma certa importância, não é porque bruscamente se descobriu, como campo de pesquisas empíricas, essa potência surda, inesgotavelmente rica, a que se chama a natureza; não é também porque se isolou no interior dessa vasta natureza, uma pequena região singular e complexa que seria a natureza humana. De fato, esses dois conceitos funcionam para assegurar a interdependência, o liame recíproco da imaginação e da semelhança. De certo que a imaginação não é, em aparência, senão uma das propriedades da natureza humana, e a semelhança um dos efeitos da natureza (FOUCAULT, 2002, p. 97-98)

É a apresentação da natureza e da natureza humana que permite a harmonia entre a semelhança e a imaginação, uma vez que colocam no corpo geral do conhecimento as duas instâncias, a primeira por sua 
ligação com a natureza e a segunda por sua ligação com a natureza humana. "Natureza e natureza humana permitem, na configuração geral da epistémê, o ajustamento da semelhança e da imaginação, que funda e torna possível todas as ciências empíricas da ordem." (FOUCAULT, 2002, p. 98)

Nestas ciências empíricas, o domínio das naturezas simples se mostra facilmente ordenado pelo cálculo, já o das naturezas complexas exigem outra empreenda: é aí que ocupa o seu lugar a taxinomia. Em verdade, constitui o mesmo processo, enfim, se realiza como máthêsis, só que a cumpre a partir do complexo, valendo-se dos signos para ordenar a realidade no sentido do simples. Mais do que isso, a taxinomia é responsável pelas articulações, as ligações e agrupamentos que permitem na superfície das coisas observar suas diferenças e suas identidades. Papel importante desempenha ainda a visão de um tempo universal, capaz de ordenar cronologicamente os diferentes processos e suas gênesis. Desse modo,

(...) a epistémê clássica pode se definir, na sua mais geral disposição, pelo sistema articulado de uma máthêsis, de uma taxinomia e de uma análise genética. As ciências trazem sempre consigo o projeto mesmo longínquo de uma exaustiva colocação em ordem: apontam sempre para a descoberta do elemento simples e de sua composição progressiva; e, no meio deles, elas formam quadros, exposição de conhecimento, num sistema contemporâneo de si próprio. O centro do saber nos séculos XVII e XVIII é o quadro. (FOUCAULT, 2002, p. 103)

Nessa epistémê geral, a linguagem é ainda importante porque seu signo representa as coisas por ordens sucessivas. A continuidade, a linearidade requerida aos processos encontra na linguagem o caminho justo de uma explicação conectada pela apresentação seqüencial. Nada se dispõe de maneira pronta ao pensamento, e ao signo lingüístico cumpre este papel de representação das mudanças numa ordem temporal. É também a condição deste signo que permite ao pensamento analisar-se a si próprio. Além de apresentar uma "representação reduplicada", a linguagem revela a sucessão que cabe ao próprio do pensamento, a disposição espacial de uma linearidade temporal, uma sucessão de fatos que retratam de maneira espontânea o intimo da atividade intelectual. Esta visão do signo lingüístico e do pensamento permite ao homem deste período pensar a linguagem como a mais elementar manifestação de uma reflexão sobre o próprio saber. O conhecimento encontra nas raízes da língua, naquilo que a fundamenta, a característica geral de um processo conduzido por uma série histórica de disposição da linguagem sobre si mesma. Ou seja, ao mesmo tempo em que a língua demonstra a inclinação espontânea à auto-reflexão, uma vez que rompe com o imediato e coloca o mundo em seqüência, capta em seu corpo, em sua marca, o conjunto de tropeços e acertos que caracterizaram o desenvolver desta espontânea construção.

E essa dependência da língua relativamente ao saber libera todo um campo histórico que não existira nas épocas precedentes. Algo assim como uma história do conhecimento torna-se possível. É que, se a língua é uma ciência espontânea, obscura a si mesma e inábil - em contrapartida é aperfeiçoada pelos conhecimentos que não se podem despontar em suas palavras sem nelas deixar seu vestígio e como que o lugar vazio de seu conteúdo. As línguas, saber imperfeito, são a memória fiel de seu aperfeiçoamento. Induzem em erro, mas registram o que se apreendeu. Em sua ordem desordenada, fazem nascer falsas idéias; mas as idéias verdadeiras nelas depositam a marca indelével de uma ordem que o acaso somente não poderia dispor. O que nos deixam as civilizações e os povos como monumentos de seu pensamento não são tanto os textos, mas sim os vocabulários e as sintaxes, os sons de suas línguas mais que as palavras que as pronunciaram, seus discursos menos que o que os tornou possíveis: a discursividade de sua linguagem. (FOUCAULT, 2002, p. 121)

Esta linguagem, de todo modo, se mostra refém do seu caráter discursivo, já que é a temporalidade imposta ao verbo que permite pensar a língua dessa maneira, e, com ela, a apresentação de uma ordem de sucessões para o mundo. O absoluto só encontra na linguagem, no verbo, uma única representação, o ser, o "é" que fundamenta e articula toda a proposição. Limitando-se a ele, nada poderia se explicar, pois não haveria sucessões, tão somente a expressão atemporal de algo sempre ou simplesmente existente: é porque "é", esta seria a resposta última de toda a análise, o bater de pé de um pensamento infantil e teimoso. 
Na sua raiz, o progresso, tal como é definido no século XVIII, não é um movimento interior à história, é o resultado de uma relação fundamental entre o espaço e a linguagem. (...) A linguagem confere à perpétua ruptura do tempo a continuidade do espaço, e é na medida em que analisa, articula e recorta a representação, que ela tem o poder de ligar através do tempo o conhecimento das coisas. Com a linguagem, e monotonia confusa do espaço se fragmenta, enquanto se unifica a diversidade de sucessões. (FOUCAULT, 2002, p. 159-160)

Desse modo, a ordem, no centro da epistémê clássica, encontrará na língua a chave da explicação processual e a representação do mundo.

É desse papel da linguagem que nasce a História Natural. Foucault (2005) aponta esta visão seqüencial e o caráter da nomeação como as chaves para a ascensão de uma nova forma de se analisar a natureza. Estruturada sob o signo lingüístico, participará do mesmo corpo geral da epistémê clássica, procedendo inclusive por exclusões, restrições do observado e encontrando na palavra o que se aludia em outros campos ao cálculo. É a ordem, representada na linguagem, na sua disposição cronológica e no seu caráter seqüencial, que permitirá a realização do projeto de uma história da natureza; é a língua, a sua ligação com a epistémê geral, e não o aumento das informações no período, que determinará o avanço desta ciência. $\mathrm{O}$ autor pretende com isso mostrar que não é a simples leitura de um movimento histórico e suas materialidades que permite o entendimento da realidade e a formação do conhecimento, mas a ligação e interdependência entre uma materialidade sensivelmente identificada e os atributos de uma reflexão sobre esta mesma materialidade. É também nesse projeto da ciência natural que a linguagem encontrará sua plena forma clássica, funcionando como representação, deixando definitivamente de confundir-se com as coisas para classificá-las, dispô-las em ordem.

O papel da linguagem, este crivo descritivo que representa o aparente, explica o caráter superficial das classificações e do procedimento da História Natural; ela é, nesse período, a língua capaz de retratar a natureza, a descrição, a representação do visível, da estrutura percebida em sua externalidade. É ainda por isso que desempenha papel tão importante a botânica, afinal, as plantas revelam em sua forma a manifestação de sua estrutura muito mais do que os animais, por exemplo. É também por isso, e pela função da linguagem na visão de um contínuo, que podemos vislumbrar uma ligação entre as coisas do mundo; não em seu interior, mas no espaço mesmo onde se desenvolvem. Aqui, ainda não é possível falar em evolução como hoje a entendemos, a continuidade não está nas coisas, está fora, na disposição geral do globo e suas revoluções; o tempo é contínuo, universal, e não se altera por um jogo interior ou coisa que o valha.

A história natural, na idade clássica, não corresponde à pura e simples descoberta de um novo objeto de curiosidade; recobre uma série de operações complexas que introduzem, num conjunto de representações, a possibilidade de uma ordem constante. Constitui como descritível e ordenável ao mesmo tempo todo um domínio de empiricidade. O que a aparenta às teorias da linguagem a distingue do que nós entendemos, desde o século XIX, por biologia e a faz desempenhar no pensamento clássico um certo papel crítico. (FOUCAULT, 2002, p. 219)

Mas Foucault (2002) nos adverte que não se aplica somente às teorias a disposição geral da epistémê de um período, ela se estende para toda a vida, se emaranha com a prática, com as formas de proceder dos homens. Por isso, enxergará o autor a manifestação desta epistémê também na economia, nas relações de troca estabelecidas entre os homens. Evidentemente, também incidirá sobre a visão que temos desta prática, enfim, ocupará a epistémê geral todos os níveis da realidade.

Como vimos, na parte que denominamos histórica, o valor da moeda era dado pela quantidade de metal que a compunha. Foucault (2002) dirá que esta forma de conceber a moeda é fruto de um processo de similitudes, que pretende identificar o valor por algum outro referencial material; é assim que a moeda aparece como uma mercadoria entre as outras; é ainda por isso que ocorre um aumento dos preços quando da descoberta de metais preciosos nas Américas. Esta moeda se confunde com as coisas, empresta delas seu valor e por elas define sua extensão ou retração. A epistémê geral do século XVI é então a das 
similitudes; o semelhante é a base de todo entendimento e ação. Será, portanto, com o advento de uma nova epistémê que se poderá romper com esta visão monetária, além de, evidentemente, iniciar-se uma nova empreenda teórica e prática.

O papel da representação na busca da ordem se estabelecerá, dessa forma, também na economia. A moeda, antes definida pela quantidade de metal que a compunha, passa a emprestar o valor da sua representação, da marca, da insígnia empregada na ordenação das trocas. A função de signo é o elemento chave de todo valor monetário. Este valor, representado no símbolo, é gerido por uma rede de circulação e de trocas. O mesmo ditame que guiara a cadeia de representações uma a partir da outra é o que rege a economia na base de trocas. $\mathrm{O}$ valor se estabelece pelo signo e se recria nas trocas, nas relações engendradas no seio de uma economia mercantilista.

Através da experiência mercantilista, o domínio das riquezas se constitui do mesmo modo que o das representações. Viu-se que estas tinham o poder de se representarem a partir de si mesmas; de abrir em si um espaço onde elas se analisavam e de formar, com seus próprios elementos, substitutos que permitiam a um tempo, estabelecer um sistema de signos e um quadro das identidades e das diferenças. Do mesmo modo, as riquezas têm o poder de se permitirem; de se analisarem em partes que autorizam relações de igualdade e desigualdade; de se significarem umas às outras por esses elementos de riquezas perfeitamente comparáveis que são os metais preciosos. E assim como o mundo inteiro da representação se cobre de representações de segundo grau que as representam, e isso numa cadeia ininterrupta, assim também todas as riquezas do mundo estão em relação umas com as outras, na medida em que fazem parte de um sistema de trocas.(FOUCAULT, 2002, p. 247)

É na reunião de uma visão da linguagem, da história natural e da economia que Foucault (2002) pretende explicar o que seria a epistémê clássica, esta busca pela ordem universal, uma máthêsis regida pelo jogo de identidades e diferenças, enfim, pela representação estabelecida na binária relação entre significante e significado. É esta epistémê clássica que dará lugar à moderna, a este novo jogo de relações teóricas e práticas que pretendemos neste capítulo analisar.

\section{A nova epistémê: o advento da modernidade}

Pretendemos, a princípio, dividir este capítulo em duas partes, mas a primeira, que chamamos histórica, é aqui retomada com o intuito de mostrar que esta historicidade é própria da modernidade, é parte do panorama geral de diretrizes que guiaram o conhecimento e a vida em seu novo curso. Esta história, contudo, é diferente daquela desenvolvida no âmbito da epistémê clássica, não se trata mais de uma sucessão de fatos em sua externalidade pelo atributo do signo lingüístico, trata-se, isto sim, de uma nova visão das mudanças sobre um pano de fundo empírico, em suas alternâncias e internas manifestações. O papel da materialidade nas transformações é evocado como chave do fluir da vida e da dinâmica da realidade. Em verdade, o cerne da visão moderna está nesta processualidade, na condução do curso histórico da linguagem, no devir da filosofia e na evolução biológica.

A procura da essência, dispersa por um longo tempo, é retomada no curso do pensamento moderno, a busca pela definição do ser, do homem, traz em si as possibilidades de seu próprio desenvolvimento, os rumos a serem seguidos e o sentido de sua existência. $O$ fim está no ser, é neste sentido que ele ruma e não pode de outro modo proceder. Na economia, a centralidade do trabalho é dada pela identificação da essência humana com o produzir, com o labor capaz de transformar toda a realidade, enfim, com a materialidade que o define e que pode ele conduzir. Requerendo para si os frutos de seu trabalho, tendo o mundo disposto ao seu alcance, enxerga o homem, na sua atividade, a forma mais clara e objetiva de seu fim último. Este homem, descoberto em sua essência, é também estranho a si mesmo, não se reconhece no curso de sua produção, na linha que traça em seu desenvolvimento. A ideologia, a subjetividade emergida para além do controle é a ratificação de um domínio perdido em vista de ser novamente conquistado, movendo o homem num jogo de busca por si mesmo. 
O homem, descoberto em sua finitude (ou aí colocado), portanto, está no seio da natureza, na materialidade que se dispõe ao seu controle e que de todas as formas se lhe submete. Mas é ainda esta finitude, este liame essencial do homem com o mundo que o faz perder-se de si, submeter-se a imposições que, para além de simples restrições físicas, penetram o seu eu, a consciência que poderia colocá-lo como senhor de todas as coisas. O anúncio da existência finita do homem é também o anúncio de sua morte, como dirá Foucault (2002). Esta mesma explicação é tomada, no caso de Marx (1818-1883), na análise da sociedade. Aqui, é a humanidade que se encontra limitada pelas máximas de uma produção espoliadora, que reprime o próprio do homem, que o joga numa miséria de suas possibilidades e faculdades. Este limite é também a fonte de sua libertação. Aqui, o otimismo de um fim alcançável pela humanidade transcende a limitação do homem como indivíduo. A história, posta em marcha, transforma esta repressão do humano em chave de sua própria superação. O limite alça toda a sociedade à extrapolação dos ditames impostos, à dissolução da ordem inibidora que subjuga a existência corrompida, quando em face de seu mais horrendo quadro. Nasce nova humanidade, ou a humanidade propriamente dita, de suas próprias amarras, dos limites concretos de sua vida.

Foucault (2002) dirá ainda que na História Natural acontece um fenômeno de mesma proporção e que reconduz ao próprio do ser, ao interior de sua "organização". Esta nova empreenda se ocupa não mais da superfície visível dos seres, de sua externalidade, mas do que lhes é próprio, a sua organização interna. Há neste projeto, o uso de uma hierarquização. São eleitos os caracteres constantes, seguindolhes os secundários e os terciários. Estes caracteres, por sua vez, estão ligados a funções, ou seja, a importância é dada não por sua ocorrência, mas em vista de um qualitativo papel representado na ordem do ser. A vida assume a centralidade na análise da natureza, afinal é nela que se pode reconhecer as funções primordiais, aquelas responsáveis pela existência mesmo do ser. É, enfim, este projeto a busca do invisível no visível, do íntimo no superficial; é o reconhecimento dos elementos essenciais tomando como parâmetro a vida. Há neste processo uma ruptura entre a classificação e a nomenclatura. Nomear os seres é diferente de classificá-los, já que na classificação se coloca a função, a organização íntima que permite identificar diferentes seres em classes ou grupos justapostos.

A ordem das palavras e a ordem dos seres não se recortam mais senão numa linha artificialmente definida. Sua velha interdependência que fundara a história natural na idade clássica e que conduzira, num só movimento, a estrutura até o caráter, a representação até o nome e o indivíduo visível até o gênero, começa a desfazer-se. Começa-se a falar sobre coisas que têm lugar num espaço diverso do das palavras. Ao fazer, e muito cedo, semelhante distinção, Lamarck encerrou a idade da história natural, entreabriu a da biologia muito melhor, de um modo bem mais certo e radical do que ao retomar, cerca de 20 anos mais tarde, o tema já conhecido da série única das espécies e de sua transformação progressiva.(FOUCAULT, 2002, p. 317)

É na fundamentação desta nova biologia que se disporá a presença de leis internas e a cisão entre orgânico e inorgânico, aquilo que tem vida e o que não tem, enfim, será este o parâmetro geral de toda hierarquização e de todo entendimento da natureza. Algo parecido com a relação estabelecida na economia entre a esfera exterior e o homem se dá entre o mundo inorgânico e orgânico. "O ser vivo, pelo jogo e pela soberania dessa mesma força que o mantém em descontinuidade consigo mesmo, acha-se submetido a uma relação contínua com o que o cerca."(FOUCAULT, 2002, p. 378). Há, na composição do ser, a necessidade do exterior, do mundo que com ele se comunica, e que de algum modo atua sobre suas condições de existência. Esta seria a chave epistêmica, por exemplo, do evolucionismo sob a perspectiva de uma seleção natural. Mas ainda que se anuncie uma correspondência direta entre os diferentes saberes, afinal estão, assim como toda a realidade, submetidos a mesma epistémê geral, não podem dizer-se filosoficamente parelhos. Cada área, cada ramo encontrará suas premissas, o caminho filosófico para a sustentação de suas teorias. Abre-se o tempo de múltiplos paradigmas filosóficos, em que se fundam as raízes da ciência de acordo com a conveniência analítica do objeto ou em virtude dos objetivos. A ruptura definitiva entre ciência e filosofia não elimina a necessidade da segunda, mas a submete 
às determinações da primeira. A filosofia deixa de ser o conhecimento essencial de explicação da realidade para se tornar a ferramenta fundadora de princípios da ciência.

Aqui se apresenta um problema central, a falta de unidade filosófica, talvez porque se tenha tão abertamente criticado e mesmo ridicularizado o que se assemelha ao absoluto, àquilo que não se aparenta com o conjunto de valiosos pressupostos que regem uma sempre relativa cena. Fizemos da filosofia jogo de faz de conta, lugar onde tudo pode e nada vale; espaço em que afirmar categoricamente é ser dogmático, e relativizar é ser sábio sem nada dizer. É o legado, sem dúvida, da crítica kantiana, mas é mais o seu esquecimento, ou melhor, o congelamento de sua imagem não resolvida, inquestionada, ainda que nos aviltemos por caminhos sólidos como a empiricidade. No fim, nada cremos de verdade, afinal, a desconfiança é marca de um tempo fantasiado pelo homem que descobre magicamente que por ele passa o mundo. A interdisciplinaridade, a transdisciplinaridade dizem respeito a esta discussão, a este abandono das resoluções filosóficas no enfrentamento da realidade. Deixando de ser simples ferramental de pressupostos, talvez um dia possa a filosofia ocupar seu lugar como único caminho razoável de compreensão, se é que é possível, da realidade.

Na linguagem também serão buscadas as funções, os radicais, a análise sintática, aquilo, enfim, que caracteriza a articulação e funcionamento do corpo lingüístico. A linguagem que antes se apoiara no discurso, na sua seqüência e no seu valor representativo, encontra agora na gramática, nas flexões e nas ligações possíveis o seu sentido analítico. A historicidade permeia o domínio lingüístico; se liga com o processo de formação das palavras, mais do que isso, explica a conexão própria que permitiu às línguas articulações coerentes e uma conexão lógica ao longo do tempo. .

Vê-se que a historicidade introduziu-se no domínio das línguas como no dos seres vivos. Para que uma evolução - que não fosse somente percurso de continuidades ontológicas - pudesse ser pensada, foi necessário que o plano ininterrupto e liso da história natural fosse quebrado, que a descontinuidade das ramificações fizesse aparecer os planos de organização na sua diversidade sem intermediários, que os organismos se ordenassem às disposições funcionais que eles devem assegurar e que se estabelecessem assim as relações do ser vivo com o que lhe permite existir. Da mesma forma, foi preciso, para que a história das línguas pudesse ser pensada, que elas fossem destacadas dessa grande continuidade cronológica que as religava sem ruptura até a origem; foi preciso também liberá-las da superfície comum das representações onde estavam presas; graças a essa dupla ruptura, a heterogeneidade dos sistemas gramaticais apareceu com seus recortes próprios, as leis que em cada um prescrevem a mudança e os caminhos que fixam as possibiliddes da evolução. (...) Aqui, como alhures, as colocações em série cronológica tiveram de ser apagadas, seus elementos redistribuídos, e constituiu-se então uma história nova, que enuncia não somente o modo de sucessão dos seres e seu encadeamento no tempo, mas as modalidades de sua formação. A empiricidade - trata-se tanto dos indivíduos naturais quanto das palavras com que podem ser nomeados - está doravante atravessada pela História e em toda a espessura de seu ser. A ordem do tempo começa. (FOUCAULT, 2002, p. 405-407)

A linguagem tornada objeto, contudo, se mantém para a ciência como imagem do discurso, por isso é buscada uma redução, uma conformação capaz de retratar o conhecimento de maneira clara e funcionalmente ordenado. É o que criticará os românticos do século XIX, esta linguagem ainda presa ao nexo causal, limitada em vista de uma linguagem poética.

Na construção do saber moderno, transcendental e empírico se separam, o transcendente julga a partir das formas puras, da matemática, o encadeamento interno ao mundo; a empiricidade arbitra sobre a subjetividade e coloca na determinação da finitude humana as diretrizes de um mundo por ela determinado. Nas múltiplas filosofias a serviço da ciência, como antes mencionamos, constrói-se o moderno conhecimento, este emaranhando de proposições que giram em torno de uma ciência erigida em função de sua utilidade. Talvez por isso se questione a função e o papel da dissertação que agora realizamos.

Esta divisão entre o empírico e o transcendental reside, como nos fala Foucault (2002), na descoberta do homem. Posto em sua finitude, neste limite concreto que o transforma em objeto e sujeito do conhecimento; neste jogo de finitudes que transpõem os limites e anunciam o processo, a mudança operada 
a suas vistas, o homem será ao mesmo tempo lugar do transcendente e do empírico. "O homem, na analítica da finitude, é um estranho duplo empírico-transcendental, porquanto é um ser tal que nele se tomará conhecimento do que torna possível todo conhecimento." (FOUCAULT, 2002, p. 439). Neste jogo empírico-transcendental será o empírico colocado em primeiro plano, servirá de base no enunciado de uma primazia que não permite superação da epistémê posta. Não se pode, a título de heresia, duvidar da primazia da empiricidade, muito embora seja um recurso filosófico arbitrário, uma escolha em vista de um conhecimento científico. Foucault (2002) dirá que a fenomenologia pretende ser o meio-termo deste problema, desta arbitrariedade, evidentemente, sem sucesso.

Ela procura articular a objetividade possível de um conhecimento da natureza com a experiência originária que se esboça através do corpo; e articular a história possível de uma cultura com a espessura semântica que, a um tempo, se esconde e se mostra na experiência vivida. Portanto, não faz mais que preencher, com mais acuidade, as exigências apressadas que foram postas quando se pretendeu fazer valer, no homem, o empírico pelo transcendental. (FOUCAULT, 2002, p. 443)

$\mathrm{Na}$ fenomenologia estaria disposta a representação de uma subjetividade, um aspecto cultural que não tem outra origem senão a empiricidade. Ainda que se mascare indefinidamente esta objetividade pela presença de um "eu" ou um valor cultural, nada de novo se instaura com relação à arbitrariedade original de reconhecer a primazia do empírico.

Um novo exame do cogito ascende na modernidade. Trata-se não mais de um reconhecimento de ilusões, de quimeras enganadoras da mente, da lucidez que deve ser ratificada e aclarada por um método correto e preciso, trata-se, antes disso, de como enxergar o papel dessas ilusões, as quimeras loucas que escapam a consciência e que se apresentam como fomentadoras de um saber consciente. No cerne mesmo da apresentação do homem como transcendental e empírico, pode este novo cogito, esta releitura do inconsciente na formação do consciente ascender como fagulha explicativa de um impensado atuando no pensamento.

(...) todo o pensamento moderno é atravessado pela lei de pensar o impensado - de refletir, na forma do Para-si, os conteúdos do Em-si, de delinear o homem reconciliando-o com sua própria essência, de explicitar o horizonte que dá às experiência seu pano de fundo de evidência imediata e desarmada, de levantar o seu véu do Inconsciente, de absorver-se no seu silêncio ou de pôr-se à escuta de seu murmúrio indefinido. (FOUCAULT, 2002, p. 451)

Esta nova construção, a epistémê surgida com a queda da clássica, é a manifestação de uma historicidade, de um tempo, um processo, uma mudança que encontra na essência do homem, do ser vivo e da língua as chaves de todo entendimento. É, nas palavras de Foucault (2002), a busca do "Mesmo", a descoberta do que "é" para atingi-lo, a revelação do ser que ao mesmo tempo a cria, este jogo dialético que pressupõe uma ontologia desprovida de metafísica. Os sonhos, a vida, o pensamento e os sentidos atendem a este curso maior, estas diretrizes gerais colocadas pela ainda vigente epistémê moderna.

\section{Considerações Finais}

Vimos no decorrer deste artigo a questão central na modernidade da primazia assumida pela materialidade, o campo das finitudes, e, ao mesmo tempo, apontamos com esta resenha de "As palavras e as coisas" uma outra perspectiva de análise que pretende não só uma leitura diferenciada para a questão de uma continuidade no desenrolar da epistémê moderna como também a introdução de uma possibilidade analítica que busca romper com os determinantes restritos da epistémê posta. Pretendemos, portanto, apontar um problema central na modernidade, o da ontologia do saber e da realidade.

A leitura ligada a espitémê moderna, gestada por ela, chamamos histórica; ela se delimita no campo de uma materialidade em transformação, um regimento interno as coisas capaz de guiar toda a existência, as variações da objetividade e da subjetividade (LÚKACS, 1968). Conduzidos pela matéria, pelas 
modificações concernentes ao seu processo de auto-recriação, seguimos como personagens e autores, ainda que enredada seja a peça por uma determinação primeira, a matéria de que emerge todo fluir imperioso. Esta leitura é moderna, não pode deixar de ser, analisa modernamente o curso da modernidade; insere-se no curso de uma busca colocada pelo movimento que pretende descrever, assiste impaciente as contradições que pretende superadas, coloca o transcendente no verso de uma página empírica; enfim, se muni de modernas armas para a própria modernidade enfrentar. Sonha esta visão ver suplantada a condição que criou seu existir pela dinâmica própria que leva toda a materialidade ao novo. No afã de um desejo moderno, sonha o fim da modernidade, alimenta a esperança pueril de uma promessa guardada na origem mesmo de toda a matéria, não sem razão, afinal, consegue ver diante dos seus olhos suas máximas afirmadas, enxerga no curso da história humana a dinâmica que reconhece como a verdade anunciada. Mas eis que estas explicações já não bastam, seja pela incoerência disposta por uma organização cosmológica incoerente, seja pela arbitrariedade no favorecimento da empiricidade, seja ainda pela própria ineficácia da história em suplantar uma modernidade sempre presente. Talvez não possa porque o mundo não é o que a modernidade anuncia; talvez porque por ela nos limitamos a ordem de uma primazia primeira da matéria, ainda que tentemos nos iludir com a dinâmica pretensamente livre enredada pela objetividade e a subjetividade; talvez, ainda, porque nos mantemos reféns de uma verdade escolhida para ser vivida, um sonho que insistimos em perseguir sem nos indagarmos um instante mais sobre o que seja a realidade ou nós mesmos.

O que Foucault (2002) pretende fazer é justamente mostrar outra leitura, uma forma diferente de compreender a nós e o processo que nos criou. Percebe, de imediato, que não pode defender a primazia do empírico sobre o transcendental, escolhe não escolher, opta por engajar a percepção desta materialidade em transformação com o conjunto de variações do pensamento ao longo do tempo; define, no quadro criado entre estas duas variáveis, a arqueologia da ciências, aquilo que possibilita a visão das epistémês que dominaram os períodos analisados. Este procedimento, esta disposição analítica é, além de uma explicação, uma tentativa de ruptura, o anúncio de uma forma diferente de encarar a realidade. Esta visão que nos dispomos a apresentar coloca a realidade num jogo ininterrupto entre o empírico e o transcendental, um múltiplo agir e determinar que não escolhe referências, que não admite primazias. Mas se atentamente olharmos, existem alguns problemas.

O primeiro deles, aquele que salta aos olhos, é o não resolvido; afinal, como enfim resolve o problema da primazia, da definição de uma ontologia do saber e mesmo da realidade? Não resolve, não responde por que filosoficamente não há ferramentas dispostas para uma escolha não arbitrária. Dizer, em último caso, que a realidade é um múltiplo empírico-transcendental significa nada dizer, a não ser que não se abre uma razoável explicação da realidade. Age, portanto, na mesma linha do que pretende criticado, este uso da filosofia como ferramental da ciência, como campo de um arcabouço de princípios e pressupostos. Sua análise da realidade, a dinâmica encerrada no movimento descrito pelas variações ao longo de uma temporalidade não responde aos problemas colocados, apenas abre uma outra via interpretativa.

Um segundo problema acontece na avaliação dos conteúdos. Foucault (2002), por sua disposição metodológica, valoriza a forma, a arqueologia das idéias, nela enxergando rupturas como entre o período clássico e o moderno. Mas o que dizer dos conteúdos, como não reconhecer a modernidade na filosofia de Bacon (1979) e Descartes (1973) ou mesmo outros como Leibniz (1979) e Newton (1979)? Ainda que sejam discrepantes no que se refere ao método, na estrutura analítica que hoje ocupa as ciências, muito do conteúdo de suas filosofias se impregna na vida moderna, está em nós e mesmo no saber que imaginamos construir. É evidente que Foucault (2002) procura retratar linhas gerais e certamente não admite uma completa supressão do precedente, só que é mais do que um vestígio, mais do que um órgão inutilizado aquilo que a modernidade incorpora da epistémê clássica. Há mudanças importantes, e sua explicação é bastante eficiente no esclarecimento dessa questão, mas os conteúdos estão vivos, fazem parte e compõem a teoria e a prática moderna.

O terceiro e último problema identificado é o mais complicado e mantém, de algum modo, o pensamento de Foucault (2002) na linha de frente da modernidade, indicando a impossibilidade de uma 
superação da epistémê ou estrutura hoje existente. Este problema é o do tempo, mais precisamente da dinâmica da realidade. Há, seja no período clássico, seja no período moderno, a visão de uma dinâmica: no primeiro caso, dado pelo exterior, por uma ordem temporal impositiva e homogeneizante (tributário da linguagem como queira Foucault), no segundo caso, pela organização interna as coisas, uma expressão mesmo de tudo o que existe. De qualquer forma, há uma alternância, uma variação imposta à realidade que pode ser mensurada na visão de um tempo, seja ele absoluto ou relativo. Esta dinâmica, o contínuo transformar da realidade não pode ser retirado da análise de Foucault, afinal, se ela desaparece-se, desapareceria a própria explicação, já que trata-se de uma análise por períodos, que busca identificar uma variação, uma mudança realmente existente. A admissão de um movimento da realidade não é e não pode ser abandonada. Mas por que não pode? Não pode porque não haveria explicação possível. A análise e a explicação são reféns da alternância, do curso, da seqüência que garante coerência lógica ao raciocínio e que permite mesmo a comunicação de todo entendimento. Seria impossível explicar a realidade sem o recurso da mudança, da dinâmica envolvendo toda a vida. Mas não será justamente este o ponto limitador, o anúncio de um homem incapaz de exercer-se para além da razão ou desta racionalidade posta? Não será o caso de imaginarmos outra possibilidade? Recorrendo ao que deixado fora pelo caminho, como a própria questão colocada pelos românticos no que se refere à intuição, não poderíamos sentir a realidade antes de pensá-la, fazer parte dela antes que dominá-la ou defini-la, ser ao invés de explicar o ser? No absoluto, na supressão total de toda horda que nos toma, talvez exista a única resposta possível de um caminho necessário porque existente, a de que as coisas são o que são porque tudo é o que "é". Quimera de um homem que, como disse Foucault (2002), com sua finitude anuncia sua morte, um fim que o leva possivelmente para além da razão, para além da explicação, para além do que hoje possamos imaginar possível ou mesmo aceitável.

Neste artigo, apresentamos a proposta de Foucault em "As Palavras e as Coisas", bem como as possibilidades e limites que suscitam esta obra no debate central e ainda aberto na Filosofia: o debate empírico-transcendental.

\section{Referência Bibliográfica}

BACON, F. Novum organum ou verdadeiras indicações acerca da interpretação da natureza; Nova Atlântida. São Paulo: Abril Cultural, 1979. (Os pensadores)

BRANCO, João M. de F. Dialética, ciência e natureza. Lisboa: Caminho, 1989.

COMTE, August. Curso de filosofia positiva; discurso sobre o espírito positivo; discurso preliminar sobre o conjunto do positivismo; catecismo positivista. Trad. José Arthur Giannotti e Miguel Lemos. 2. Ed. São Paulo: Abril Cultural, 1983.

DESCARTES, René. Discurso do método; Meditações; Objeções e respostas; As paixões da alma; Cartas. São Paulo: Abril Cultural, 1983. (Os pensadores)

ENGELS, Friedrich. A Dialética da Natureza. Editora Paz e Terra. Rio de Janeiro, 1985.

FOUCAULT, M. As palavras e as coisas. São Paulo: Martins Fontes, 2002.

GARAUDY, Roger. Karl Marx. Zahar Editores, Rio de Janeiro, 1967.

HAVEMANN, R. Dialética sem Dogma. Zahar Editores. Rio de Janeiro, 1967.

HEGEL, G. W. F. Fenomenologia do espírito. Trad. Paulo Meneses; com colaboração de Karl-Heinz Efken e José Nogueira Machado - 5a . Rio de janeiro: Ed. Petrópólis, 2008.

. Introdução à história da filosofia. São Paulo: Ed. Abril, 1974 (pp. 321-398) (Col. Os Pensadores)

LEFEBVRE, H. Lógica formal / lógica dialética. Rio de Janeiro: Civilização Brasileira, 6A. ed., 1995

LEIBNIZ, G. W. A monadologia; Discurso de metafísica; Correspondência com Clarke. São Paulo: Abril Cultural, 1979. p. 101-232 (Os pensadores)

LUKÁCS, Georg. Realismo e existencialismo. Lisboa: Arcádia, 1968.

MARX, Karl \& ENGELS, F. A ideologia alemã; Feuerbach - a contraposição entre as cosmovisões 
materialista e idealista. São Paulo: Martin Claret, 2008.

MARX, Karl. Manuscritos econômico-filosóficos e outros textos escolhidos. Sel. José Arthur Giannotti. São Paulo: Editora Abril Cultural, 1974

MOREIRA, Ruy. O círculo e a espiral: a crise paradigmática do mundo moderno. Rio de Janeiro: Obra Aberta, 1993.

Trabalho enviado em janeiro de 2009

Trabalho aceito em agosto de 2009 